\title{
Challenges to public engagement in science and technology in Japan: experiences in the HapMap Project
}

\author{
EIKO SUDA, DARRYL MACER \& ICHIRO MATSUDA ${ }^{1}$
}

\begin{abstract}
Public engagement in science and technology has grown in importance as developments in science and technology make increasingly significant impacts on people's lives. Now, efforts to engage publics in social decision-making or consensusbuilding regarding science and technology involve participation, learning or deliberation opportunities, as well as interactive or coproductive efforts among various sectors in society based on the recognition of scientific activities as a part of social operations - even those performed by scientific communities. We have conducted a community engagement program in the HapMap project, the international human genome program, in Japan since 2002. Consequent upon our various approaches to engage Japanese publics, a range of observations were made, such as that: public engagement is not yet recognized or institutionalized in Japan; there is a wide gap between science and society; and the implications of public engagement in a Japanese context have not been examined enthusiastically, especially from the perspectives of political decision making, social consensus-building or selfdetermination. In this paper, we provide an overview of public engagement in Japan, and discuss issues and challenges raised by the HapMap community engagement project. We also discuss the implications of public engagement for social decisionmaking and self-determination, and explore the prospects for public engagement in science and technology in Japan.
\end{abstract}

\section{Introduction}

\section{Background: public engagement in Japan}

There have been attempts to engage the public regarding particular applications of science and technology in Japan since the early efforts to gain acceptance of nuclear energy production. What could be called public engagement (PE) has been attempted in various spheres, including the development of technology assessment (TA), progress in regulatory sciences, risk communication, advancement of ethical, legal and social implications (ELSI) studies, since the 1970s. However, PE approaches have remained limited in scope and consequently they have still not taken permanent root in science and technology fields in Japan. ${ }^{2}$ In contrast to many advanced countries where TA is operated continuously under established frameworks with 
systematic evaluation methodologies, there is no permanent framework for TA in Japan yet. ${ }^{3}$ Institutionalization of PE in scientific research or technology development is an important need.

The Human Genome Project of the $1990 \mathrm{~s}^{4}$ was a significant catalyst for ELSI studies in many countries. While significant resources are allocated to science and technology in Japan, less than 1 per cent of the total human genome research budget has been spent on ELSI purposes so far, despite this point having been discussed internationally since $1992 .{ }^{5}$ The recent reforms by which national universities became independent administrative entities in 2004 have not helped, as universities are interested in promoting research investment with short-term achievements or benefits, so that ELSI studies tend to be disadvantaged. ${ }^{6}$

While the slogan a "nation based on the creativity of science and technology" has been advocated as national policy for long time in Japan, the white paper on science and technology published in $2004^{7}$ highlighted the concern that science and technology are held in low regard by lay people, and repeated the call for improved science literacy among the public. The white paper introduced the concept of PE in science and technology as a strategy to promote more interactive communication between science and society rather than following the dominant top-down styles. Scientific communication was encouraged as a part of scientific policy to improve science literacy in society generally. However there is still little research on the objectives, roles and functions of PE, nor on the appropriate methodologies and evaluation methods in Japan.

Currently in Japan the public at large, including sectors such as government and industry, and scientific communities as well as lay people, understand PE as a strategy for the development of public acceptance of science and technology. This is close to a deficit model concept of public understanding of science (PUS) rather than positive $\mathrm{PE}$ as seen in recent modern movements. Simply, it may be viewed as an extension of public relations, rather in the way that the concept of ELSI is often recognized only in the context of obtaining informed consent. 


\section{The International Haplotype Mapping Project}

The International Haplotype Mapping (HapMap) Project ${ }^{8}$ is an international collaborative project to determine the common patterns of DNA sequence variation across the human genome by genotyping four populations in the world including persons of Japanese, Han Chinese, Northern and Western European and Yoruban ancestry. ${ }^{9}$ The project was initiated in October 2002 by the International HapMap Consortium, which consisted of organizations and institutions in five countries: USA, Japan, United Kingdom, Canada and China. It mapped the regions of the genome inherited over the generations (haplotype blocks represented by the set of single nucleotide polymorphisms (SNPs)).

This project is positioned as post-Human Genome Project and its products have been enthusiastically expected to empower progress in life science research in the "postgenome age". The database, including the developed HapMap and the cell bank of collected samples which was created in Coriell Cell Repositories, ${ }^{10}$ has been made freely available in the public domain to be utilized for life science research by researchers across the world.

The project set out to identify human haplotypes, the patterns of common variation in DNA sequences across the world human population, and to develop a haplotype map, by genotyping four populations (see above). Even though the project based the HapMap on human beings in general rather than particular groups, ${ }^{11}$ much genetic information regarding the populations under study might become apparent through the process of developing the map and its utilization, since the map is freely accessible to anyone in the world. Also, the samples collected for the project are stored in the central cell bank permanently and have already been made available for researchers. Therefore, the impact on those participating - both as individuals and as communities - needed to be considered, not only before but also after the project. A community engagement and sample-collection group was organized in every participating community to work out the best process to respect each community's social, cultural or historical background. ${ }^{12}$ The mission of the group work was to provide information about the HapMap Project, including scientific background, ELSI issues regarding such research, risks and benefits of participating in the project, both for individuals and the community, and to collect the responses, questions, concerns or opinions from the community. Also, based on the knowledge from the community engagement process, the groups developed culturally appropriate protocol modifications for sample collection, including the informed consent process, sample management, and 
privacy protection in each community. ${ }^{13}$ The research described below was conducted as part of the Japanese community engagement/public consultation work of the sample-collection group of which the authors were members.

\section{Community engagement in the HapMap project}

\section{Location}

When we refer to race or ethnic group, various factors including historical, geographical, linguistic and cultural background should be considered, rather than only biological or genetic ones. Japanese residents comprise a mixture of populations with various geographical backgrounds and ancestries including indigenous people and persons of other Asian ancestries. Therefore it was not easy to define the criteria for "Japanese" even for scientific purposes. This is one of the critical topics that should be considered carefully in any country, even in one often perceived to be more homogenous than countries with greater ethnic diversity.

In Japan there are about 128 million residents $(127,694,000$, Oct. 1, 2003), and almost one tenth, more than 12 million, live in the Metropolis of Tokyo. ${ }^{14}$ Considering that the Metropolis of Tokyo developed as "Edo" town in 1603, that it is relatively new historically, and that major population growth has occurred in the past 150 years since the Meiji era, the current residents could be viewed as reflecting the mixed population of Japan more than anywhere else in the country. Also, since it is a big city, the population of Tokyo might be expected to include persons of various different social backgrounds and to reflect the attitudes of many social groups existing in Japan. Based on such considerations, the area around the Metropolis of Tokyo was thought to be an appropriate project site for the HapMap project.

\section{Target groups}

The HapMap project used the term "community engagement", as has been popularly used in the USA over the past decade. The HapMap community engagement project for Japan was conducted from early 2003 to the middle of 2004. A variety of communities were targeted both inside and outside of Japan. A variety of methods were used, including opinion surveys on selected communities, information lectures and academic conference meetings in different locations, including outside of Japan, to gather input from Japanese living abroad, and meetings held in Japan. The International HapMap project demanded community engagement efforts at participating project sites, ${ }^{15}$ with significant influence from North American concepts 
that it was required to consult the communities being approached, at least, if not the public in general.

The recruitment of public participants to the HapMap project meetings was announced in a number of ways, for example via the Internet on the Japanese project's Eubios Ethics Institute website, ${ }^{16}$ through mailing lists, newspaper flyers, posters, and leaflets dropped into mailboxes.

\section{Community engagement team and meetings}

The community engagement team included the authors, who have backgrounds in medical genetics and bioethics. We held 12 events, comprising two public forums and 10 exploratory meetings, which involved around 200 participants altogether from a broad range of social sectors including lay people and people from related sectors or from citizens' groups interested in the topics, as well as experts from various fields (eg, genetics, law, sociology, politics, ELSI. The team assessed the meetings afterwards and examined any conflicts of interests, potential harms to the donors, and other ethical issues raised.

Also, we approached other communities with certain related backgrounds, including high scientific knowledge, experience in hospitals, biotechnology related industries or companies, and so on. This yielded a further 320 participants through nine exploratory meetings.

In the meetings, participants were provided with information about the project, including scientific background to the HapMap project, ELSI issues concerning individuals and communities, as well as about the informed consent process. This was followed by questions, answers and discussions.

Following meetings for community engagement among potential donors, participants were asked to contact the organizers if they decided to donate a blood sample for the Project. Donations were only accepted from those who had attended the meetings. 
A permanent community engagement board was established after the samples were collected for the function of post-use review of the applications to use the samples. If any application was judged by the administrators of the samples to be potentially controversial, the board was available to review the application. The board members included medical and non-medical scientists, bioethics experts, media and consumer group representatives. ${ }^{17}$ A newsletter was published to make the information public. ${ }^{18}$

\section{Interviews}

To understand the Japanese situation regarding genetic research from a multidisciplinary perspective as part of PE, we conducted personal interviews with around 20 experts including scholars in genetics, law, politics and ELSI, as well as individuals from citizens' groups interested in related fields.

\section{Results, analysis and discussion}

Public engagement to empower ordinary people

\section{$\underline{1 . \text { Basically positive attitudes among general public in early phase }}$}

Both in exploratory meetings and public forums, lay people in particular expressed positive attitudes toward medical/scientific research in terms of its social contributions or helping other people. Examples of opinions expressed by meeting participants include:

A: If it will be useful for the medical science research, [I would like to donate a sample].

B: It will be my pleasure to contribute to academic research.

C: I feel that my blood will contribute to the welfare of humankind.

According to survey research conducted in 2003, ${ }^{19}$ generally positive attitudes toward genome research and DNA banking for a range of research purposes, including the HapMap project, were expressed across Japanese society. People spoke openly about their willingness to contribute to science and to help others. We observed a similar tendency during PE for the HapMap project. This continues a trend observed in 
survey research conducted since the early 1990s in Japan that basically Japanese people exhibit generally positive attitudes towards science and biotechnology based on their high expectations of it. ${ }^{20}$

\section{Diverse public opinion}

Consistent with results of earlier surveys, we identified a variety of ideas held by the public in Japan. ${ }^{21}$ Such diverse opinions cannot be easily categorized into positive or negative responses. The provision in the meetings of various information, the sharing views with others, the emergence of issues during discussion, and so on, led to the participants expressing more complicated opinions:

D: If it will be used effectively, I will donate because I can understand it is necessary that the bank has a sufficient number of samples. But I will donate on the premise that the samples will go to the public institutes. I never donate my blood to any private companies.

E: If the result will be utilized for myself, I will donate my blood ... [but] I'm not sure whether I can accept or not the use of samples and data if they are kept by researchers for other purposes.

Diversification of opinions was also identified through focus group meetings on the subject of life and biotechnology held in 1999-2000 in Japan. ${ }^{22}$ A similar diversification was shown in the responses to the questionnaire survey, which asked for responders' consideration rather than responses to simple multiple-choice questions. ${ }^{23}$ Lay people's attitudes in particular tended to change depending on when, how or in what kind of context the information was provided. While Japanese people are very familiar with biotechnology and genetics and have been exposed daily to information regarding these topics since the $1990 \mathrm{~s},{ }^{24}$ they are obtaining most information passively or in a uni-directional manner from television programs, newspapers, or the Internet, rather than in an interactive or educational context. Their opinions need to be cultivated and consolidated through interactive, learning or deliberative opportunities, for example, in order for them to be able to express their reasoning and ideas. 
3. Confusion and embarrassment observed among lay people regarding the HapMap $\underline{\text { Project }}$

It was not easy for lay Japanese people to understand specifically the highly public nature of the HapMap project, which produces a fundamental research platform and resource to contribute to a wide spectrum of future genetic research in the world. Even with a basic comprehension of its purpose or significance, as well as its associated risks, they were not empowered to compile and express their opinions. Especially among lay people without a scientific background, some showed the transition from initial positive feelings and high expectations towards more confused or reluctant attitudes through PE:

\section{F: I can't understand such a technical matter.}

G: I'm an amateur so I'm not confident to raise proper opinions.

H: It might be easier for me to just donate my sample without participating in such activities [PE].

Such potential embarrassment was one of the main obstacles to lay persons' active involvement in the dialogue of the engagement meetings. Although they don't need to have the same level or quality of knowledge as experts in order to offer their opinions as informed citizens in the engagement process, it is necessary for lay people to be empowered if they are to do so.

\section{Attitudes of participants with scientific backgrounds}

On the other hand, even in the communities of people that had a reasonably high level of scientific literacy (still considered lay people since they did not belong to expert communities or were not scientific researchers, though some may be working in biotechnology-related sectors such as industry or hospitals), difficulties were observed in the engagement process. There was evidence that, when discussions included people who were relatively familiar with genome research topics as a result of their job, for instance, and who could understand the scientific background of the HapMap project and who expressed a strong willingness to contribute to it without significant fears, the nature of discussions in general public meetings became skewed towards scientific matters rather than focusing on social or ethical aspects. For example: 
I: It [the HapMap project] is quite understandable for me so I don't need to attend the meeting before donating.

J: Spending a long time and talking about very familiar topics is sort of a burden for me. I'm not worried about donating my blood.

\section{Elements of literacy for PE}

The diversification in the HapMap project community engagement dialogue did not necessarily depend on the level of mere science literacy. It is necessary to examine the elements of literacy, other than the scientific, that are needed for the consideration of issues regarding science and technology, as well as the methodologies and environment through which such literacy can be developed. Education in general science and bioethics is a basic premise, and based on that, specific elements of literacy in individual science and technology topics are also significant in the actual PE process.

Also every member from a variety of social sectors should be helped to understand the bounds of scientific knowledge as well as the uncertainty of scientific facts, when they participate in the PE dialogue.

Excessive, simplistic and groundless expectations, as well as concerns about science and technology, might be moderated by the recognition that scientific knowledge is only guaranteed at that point under particular/laboratory conditions and may not be ensured in future or in practical social circumstances. Many social issues regarding science and technology include the region that Weinberg called "trans science" 25 matters that are necessary to develop social consensus at this moment, despite the fact that even natural or social scientists cannot answer some of the above-mentioned questions.

\section{$\underline{\text { 6. Developing opportunities for interactive discussion and sharing views }}$}

Interactive communication in which opinions and views were shared among participants or people in different sectors was observed to contribute to an increase in 
people's confidence about their understandings/opinions of the HapMap process. Qualitative types of literacy might be more important to the PE process than quantitative types. Learning and sharing views through interactive dialogue between individuals and across different social sectors might enhance that qualitative phase. By including participants from a wide range of social sectors including citizens' groups, experts' communities, etc., a public engagement process might construct opportunities to exchange diverse information and knowledge within society. In this context it should be recognized that participants in the PE process will have varying degrees of literacy, and that each stakeholder will come to the discussion from a different background. Furthermore, a variety of comprehensive and pluralistic methodologies for engaging the public in the dialogue or assessment process regarding science and technology need to be prepared. ${ }^{26}$ Currently, few such approaches are practised in Japan.

\section{Public engagement to develop communication and cooperation based on trust}

\section{$\underline{1 .}$ Trust issues among social sectors}

Some strong scepticism was expressed toward the public engagement process or the HapMap project from some social sectors. For example:

$K$ (consumer group staff): You should not be involved in such a process [PE] to justify controversial genome research if you don't want to be recognized as its instrument.

$L$ (citizens' group member): I think you are making excuses for the project by involving lay people who cannot understand the technical matter at all. This is public relations posing as community engagement.

It seems that the difficulties in understanding the Project caused and increased such scepticism, especially among those with backgrounds of distance or distrustfulness toward science and technology, which has been observed among social sectors including experts' communities in social science, citizens' groups and lay people towards biological science. Furthermore, the delicate nature of the HapMap project, in that it deals with genome diversity between human races, might have made the situation more complicated. 
Another source of distrust, which was found outside the general public or citizens' sectors, concerned doubt regarding lay people's capability to understand technical matters. For example:

Expert M (bio-industry worker): Real lay persons may not be able to understand anything about the project, [they are not appropriate as representatives].

Expert N (geneticist): In general uninterested [in scientific research program] people don't come to even the explanatory meetings.

Expert O (geneticist): You had better not explain risks too much including ones with low possibility, otherwise lay people will have too much fear and distrust toward the research and will refuse to donate samples.

Such a sense of distrust might be based on stereotypes, which have often developed as a result of a few direct or even indirect bad experiences rather than through any continual and interactive communication efforts. Even if we provided complicated information about both benefits and risks to meeting participants, they were able to understand at least some of the Project, and sometimes used that information to develop their opinions or decisions. While some people changed their positive attitudes, expressing serious fears, others became more supportive of the HapMap Project.

Wynne has used the term "institutional neuroticism" to describe diffuse anxieties and the lack of trust within scientific communities towards the public, ${ }^{27}$ Some scientists say that lay people or society don't trust scientists or science and technology, despite their not understanding technical matters; but scientists don't trust lay people, either. The distrust towards science and technology that exists within society might be caused primarily by the scientific communities themselves. The efforts to promote their scientific pursuits from social or public perspectives, not just their scientific ones, and to develop communication with the public regarding their activities have long been inadequate among the scientific communities in Japan. Without such efforts by scientific communities, they cannot expect a relationship of mutual trust to 
develop, but such a relationship could be established through practical endeavours to understand each other through interactive and sharing opportunities.

\section{Opportunities for Scientific Researchers to engage with Citizens}

As can be seen in the denial of deficit theory by reports such as Bucchi and Neresini's, which showed that the more people knew, the more they expressed concerns $^{28}$, there is a wide gap between what experts or policy-makers consider they know and the real situation. To really grasp these gaps in understanding, it is important for people to experience the dialogues for themselves. PE processes can provide that experience for people involved in the research program or scientific communities. Issues that scientific communities should or would like to know about include: the background to public attitudes; the context in which people recognize or understand topics or issues; what they expect from science; and what concerns them about it. In the efforts that scientific researchers make to understand citizens through opportunities such as PE, it is important to involve and cooperate with expert actors who can work as a bridge between science and society.

Scientific decisions by experts should not necessarily always be respected over opinions expressed by citizens on the basis of their discrete or specific experiences. Also, a scientifically reasonable decision is not necessarily always coincident with the outcome of proper social political decision-making. The understanding of such realities of the situation of science and technology related to social decision-making by every social sector can become the foundation of co-operation regarding science by all of society through opportunities such as PE.

\section{Challenges for Public Engagement in Japan}

\section{$\underline{1 .}$ Examination and authorization of the engagement process}

Some serious concerns regarding the HapMap project and the engagement activities themselves were raised by experts from the sociology, law and bioethics communities. For example: 
Expert P (law): How will you control the discriminating sentiments of some Japanese people toward certain ethnic groups?

Expert P (law): Do you have any particular idea how to handle the situation easily caused by Japanese nature that people who express strong opinions tend to have too strong initiative in the focus group meetings?

Expert $Q$ (sociology): Who can be appropriate representatives of society?

Expert $R$ (bioethics): It is problematic that you don't have any systems to monitor and maintain transparency of the Project, especially from outside.

In Japan social science research, including public engagement studies, does not need to be approved by Institutional Review Boards (IRBs) ${ }^{29}$, in contrast to the situation in many other countries in which all types of research with human subjects have to be examined and approved by independent organizations before they are carried out. So, although the process did obtain the approval of the IRBs as part of the donation process, the community engagement related to the HapMap project was not examined or authorized by anyone independently. Based on our anecdotal evidence, it would seem that most IRBs in Japan consider themselves overworked with applications for projects involving biological samples and thus cannot afford to deal with applications from general social science studies, unless some risk of psychological harm to participants is foreseen.

\section{Acknowledge position of public engagement in scientific research project structure}

For those who were in charge of the HapMap project, including researchers and funding agency officers, the pressures arising from the Project's tight schedule and the Japanese one-fiscal-year budget system imposed practical limits on the time available for community engagement. Also, as described above, due to the history of the Japanese biomedical science research environment they had had little experience of including ELSI aspects and public engagement as a routine part of scientific research programs. For example: 
Expert $N$ (geneticist): We should consider the possibility of losing willing volunteers or having people change their minds because of the burden of talking so long time [PE] with them.

Expert S (economics): I'm very negative toward ELSI in general. It is waste of resources as part of the genome project.

The quotes above might arise out of some controversial program designs of the HapMap community engagement, which was conducted in parallel with sample donor recruitment. Also, Japan's one-year research budget systems could be an obstacle to the allocation of resources to multi-year public engagement activities and research. But the project protocol design for sample donor recruitment, which was conducted subsequent to the earlier community engagement meetings in order to finish sample collections in the limited period that the Project strictly required, raised issues among the authors of this paper, ${ }^{30}$ as well as other experts. These issues are not particular to this study, or even to Japan, but to the whole question of balancing the limited funds available for public engagement and the need to progress the development of science and technology. Some expert comments included:

Expert $T$ (medical science): The relationship between community engagement through meetings and sample collecting is unclear.

Expert U (co-medical): The sample collection and community engagement should be conducted clearly independently to avoid being criticized (by people who assume that public is engaged merely in order to collect samples).

Expert P (law): The community engagement process is too investigative to conduct simultaneously with sample donor recruitment [sample collection], which must be done following strict guidelines.

Given the background of ELSI and PE with regard to science and technology in Japan described above, the function of the group in charge of the HapMap community engagement was not necessarily clearly identified even among actors/sectors involved in the Project. The community engagement was considered as a part of the informed consent process, rather than having an intrinsic mission of developing mutual communication with the public. The mission of the community engagement group became to cover the broad spectrum from sample collection to engaging the public. 
However, if the entire process from sample donor recruitment to the obtaining of informed consent is conducted by the same group members that conducted the community engagement, as it was in the HapMap process in Japan, some outside the process may not trust the validity of the sample collecting processes. Even if the community engagement team were separate from the scientific team, some critics could always say that the community engagement group was merely conducting project promotion or risk management for the Project. As a consequence, distrust and criticism might be provoked, especially from expert communities in the humanities or social sciences. Similar dilemmas and dissensions were caused even within the Project.

It is not viable to conduct PE without understanding and cooperation between every sector involved in the research project, including scientists and funding agency officers. When opposition to such efforts is common, therefore, a significant challenge is how to create within the research organization a recognition of the importance and necessity of PE or ELSI without raising suspicions of direct project promotion,.

\section{Institutionalization of PE in science and technology}

PE and ELSI research activities need to be institutionalized in scientific research or technology development programs. It is important to design the research project organization so as to delineate the primary functions of the PE group. Also, some mechanism to secure objectivity and transparency is required. In almost all examples of PE internationally, the PE elements are paid for by the scientific project, so all are open to the criticisms described above. Moreover, social dialogue should be maintained continually in the case of research such as the HapMap project, which creates products and collects materials that will be used in a variety of future research. However, under current Japanese one-fiscal-year budget systems, it is difficult to ensure the budget for multiple years of PE activities. A more flexible system, which would ensure the research budget to maintain public engagement even after completion of actual sample collecting, DNA sequencing, analysis, etc., needs to be considered. That would also allow longer periods of community engagement prior to starting the collection of samples. 
Also, the ways in which the outputs from PE can be addressed and exploited for scientific research or decision-making processes need to be examined. In the HapMap project, the engagement process was designed to generate public input to the Project, and did not aim directly to affect the research design or protocols. Even though a certain degree of support for the exercise was evident, it was very difficult to rouse ordinary people's interest to be involved in the HapMap community engagement without presenting a concrete aim of the process as output rather than contributing to decision-making, for instance. While it is not necessarily always reasonable or desirable to reflect public opinions directly in scientific research or policy settings, nonetheless we should carefully consider how to motivate the public to be involved in the PE process in scientific research programs.

\section{Necessity of comprehensive and basic studies of ELSI and PE}

The idea that a certain amount of the budget and efforts of scientific research programs should be allocated for ELSI activities was propounded by the Human Genome Project. The ELSI concept included a wide range of elements such as considering the social implications of the genome research, studying ethical, legal and social issues, encouraging public debate, and examining the methodologies for societal outreach.

The ELSI concept was then adopted worldwide and applied to scientific research in general rather than only genetic research. The EU and Canada extended the amount of and enthusiasm towards PE activities. A broad range of interdisciplinary research, which involves the public was suggested and supported in this research field, therefore various research programs were conducted among the society. In this process human resources with capabilities of PE were fostered. This process was also significant in enhancing the recognition of ELSI as well as PE both in society and among scientists.

In Japan, while the regulatory framework to conduct genome research ethically has been developed in line with international standards since the beginning of the 2000 s, ${ }^{31}$ even basic research into ethical and social aspects, which should ground the decision-making, has not been adopted enthusiastically by genome research programs. Similarly, while PE is encouraged in specific fields like certain scientific communication in recent government initiatives ${ }^{32}$, comprehensive approaches have 
not been adopted so far. Therefore, few researchers in Japan have examined the possibilities for the institutionalization of PE or ELSI studies into scientific research programs. The issues regarding PE or ELSI in scientific research or technology development are not often discussed in society, even in newspapers or TV programs. Under the current situation, neither the social recognition of PE and ELSI, nor the necessary human resources, can be developed. It might be difficult to deal with emerging ELSI issues associated with recent progress in the life sciences or transitions in social context ${ }^{33}$ without the accumulation of sufficient knowledge from basic and comprehensive ELSI studies.

\section{Conclusions}

Recently in Europe and the United States there has been a migration toward "public understanding of research" or "public engagement in science and technology" based on closer relationships between experts and the general public. Yet, while involving more sectors of the public in science and technology is indeed significant, there are only a few countries, such as New Zealand, ${ }^{34}$ which have undertaken consultations on science and technology involving more than a few lay persons.

As in many other countries, social, ethical or regulatory issues regarding areas of science and technology such as nuclear energy plants, genetically modified organisms (GMOs), tissue transplantation, infertility treatment and genetic testing, have created public arguments in Japan. Negative attitudes among the public have sometimes been seen as a serious barrier to the application of such technologies, therefore the necessity to promote social acceptance has been claimed for a long time in Japan. Nevertheless, engaging the public in the process of social decision-making has been paid scant attention by actors in scientific research programs, or by funding agencies and policy-makers.

One Japanese scholar in STS has pointed out that the participation of, and the sharing of ideas with, the public is essential for the development of appropriate riskgovernance based on the propriety of not only the political process but also issues of analytical adequacy, including in part the scientific component. ${ }^{35}$ Ordinary people can have broader perspectives on some issues than members of expert communities, and each participant expresses their attitudes based on their own frame or knowledge. To 
include their sense of value a broader range of issue framing and local knowledge from lay people is very important to complement the decision-making process by experts and policy-makers and to ensure the social propriety of decisions.

One of the immediate issues is to promote the view that coproduction with public knowledge is essential to deal with "questions which can be asked of science and yet which cannot be answered by science". 36 The recognition that direct dialogue with the public over science-based policy making should no longer be an "optional add-on" but instead a "normal and integral part of the process" ${ }^{37}$ needs to be shared by all social sectors including scientific communities, policy-makers, funding agencies and ordinary people themselves.

A significant matter is how to foster "scientific citizenry" in society, whereby persons with awareness of their own rights, duties and responsibilities consider and contribute to the decision-making process through the process of social dialogue or deliberation. Also citizens might need to be more confident about their own self-determination regarding science and technology, which should be made by individuals with responsibilities as constituent members of society. This might be one of the prospective functions of PE: to empower ordinary people to develop their selfdetermination based on civil public participation. Other aspects to be fostered through the PE process include: dialogue based on mutual trust between science and society; respect toward science as culture in society; social recognition of science as being important to citizens themselves, as well as to the next generation.

The HapMap community engagement was the first use of the word "engagement" in a Japanese genome research program. However, it did not emerge spontaneously or autonomously as the result of the situation in Japan, but was conducted in response to the requirements of the international project. A variety of challenges to PE becoming well understood/recognized and taking root in Japanese society could be identified in the HapMap community engagement process. Establishing PE as a usual part of research and incorporating a range of approaches is a future challenge for Japan. This effort will ensure that science and technology have greater civil participation and societal ownership, and also empower citizens to develop their self-determination.

\section{Acknowledgments}


We appreciate the contribution of all those involved in the HapMap process in Japan and the international community, and the support provided by the grant given to the HapMap team in Japan by the Ministry of Education, Culture, Sports, Science and Technology. We especially appreciate all the comments from participants in the meetings described, and those interviewed.

${ }^{1}$ University of Tsukuba, Graduate School of Life and Environmental Sciences, Tsukuba-city, Ibaraki, Japan fwhv4551@mb.infoweb.ne.jp (Eiko Suda); Regional Unit for Social and Human Sciences in Asia and the Pacific (RUSHSAP), UNESCO Bangkok, Bangkok, Thailand d.macer@unescobkk.org (Darryl Macer); Health Sciences University of Hokkaido, Hokkaido, Japan (Ichiro Matsuda).

${ }^{2}$ S. Kobayashi. Japan's Governmental Initiative in STS. Presented in East Asian STS conference 2003. http://sts.nthu.edu.tw/tsts/92W-paper/sinichi.pdf

${ }^{3}$ M. Haruyama. Kagakugijutsu to shakai no 'taiwa' to shiteno 'gikai technology assessment' - Europe no doukou to nihon ni okeru tenbou. Reference 2007; 675: 83-97.

http://www.ndl.go.jp/jp/data/publication/refer/200704_675/067505.pdf

${ }^{4} \mathrm{http}: / /$ www.ornl.gov/sci/techresources/Human Genome/home.shtml

${ }^{5}$ D. Macer. The far east of biological ethics. Nature 1992; 359; 770.

${ }^{6}$ T. Masui. 2005. Life science senmonka no yakuwari to kadai. In Seimei rinri no shakai teki risk management kenkyuu. Kagakugijutsu shinkou chouseihi seika houkoku sho. Ministry of Education, Culture, Sports, Science and Technology: 11-21.

http://www.jst.go.jp/shincho/db/seika/2005 s/2005 s $10 / 2005$ s 10 1 seimeirinri/2005 s 10 s 1 seim eirinri 2.pdf

${ }^{7}$ Ministry of Education, Culture, Sports, Science and Technology. 2004. Heisei 15 nendo

Kagakugijutsu no shinkou ni kansuru nenji houkoku. http://www.mext.go.jp/b menu/houdou/16/06/04060202.htm

${ }^{8}$ http://www.hapmap.org/

9 The International HapMap Consortium. The International HapMap Project. Nature 2003; 426: 789796.

${ }^{10} \mathrm{http}: / /$ www.coriell.org/ccr/ccrsumm.html

${ }_{11}$ M.W. Foster and R.R. Sharp. Beyond race: towards a whole-genome perspective on human populations and genetic variation. Nature Reviews Genetics 2004; 5: 790-796.

${ }_{12}$ The International HapMap Consortium. Integrating ethics and science in the International HapMap Project. Nature Reviews Genetics 2004; 5: 467-475.

${ }^{13}$ Charles Rotimi et al. and The International HapMap Consortium. Community Engagement and Informed Consent in the International HapMap Project. Community Genetics 2007; 10: 186-198.

${ }^{14}$ Ministry of Internal Affairs and Communications http://www.stat.go.jp/data/jinsui/pdf/2-3.pdf

${ }^{15}$ The International HapMap Consortium, op. cit, note 11.

${ }_{17}^{16}$ http://www.eubios.info/hapmapj.htm

${ }_{17} \mathrm{http://snp.ims.u-tokyo.ac.jp/CAG/JCAG/CAGmember.pdf}$

18 http://snp.ims.u-tokyo.ac.jp/CAG/JCAG/JCAG.html.ja

${ }_{19}$ M. Inaba and D. Macer. Attitudes to biotechnology in Japan in 2003. Eubios Journal of Asian and International Bioethics 2003; 13: 78-90.

${ }^{20}$ Ibid

${ }^{21}$ D.R.J. Macer,. 1992. Attitudes Towards Genetic Engineering: Japanese and International

Comparisons. Eubios Ethics Institute. 
${ }^{22}$ F. Maekawa, and D.R.J. Macer. Interactive bioethics in a focus group on life and biotechnology in Japan. Law and the Human Genome Review 2001; 15: 173-201.

${ }^{23}$ Inaba and Macer, op. cit. note 18; E. Suda and D. Macer. Policy and Attitudes towards Collection of Personal DNA in genetic databases in Japan. Journal of International Biotechnology Law 2007; 04: 8997.

${ }^{24}$ Inaba and Macer, op. cit. note 18.

${ }^{25}$ A.M. Weinberg. Science and Trans Science. Minerva 1972; 10: 209-222.

${ }^{26}$ Institute for Policy Sciences. 2000. Kagakugijutsu to shakai, kokumin no sougo sayou ni kansuru chousa kenkyuu. [English trans.: A study of interactions between science \& technology and society \& citizens.] In Kagakugijutsu to shakai, kokumin tono aida ni shoujiru shomondai ni taiou suru tameno housaku touni kansuru chousa [English trans.: A study of policies dealing with issues arising between science \& technology and society \& citizens]: 1999-2000 Kagakugijutsu shinkou chouseihi research program, funded by Ministry of Education, Culture, Sports, Science and Technology.

${ }^{27}$ B. Wynne. Public uptake of science: a case for institutional reflexivity. Public Understanding of Science. 1993; 2: 321-337.

${ }^{28}$ M. Bucchi and F. Neresini. Biotech remains unloved by the more informed. Nature 2002; 416: 261.

${ }^{29}$ In Japan, officially social science research is not obliged to be examined by IRBs, which means that such research can be conducted without examination and approval by IRBs. At least in current Japan, social science research and psychological research are not systematically obliged to be examined by IRBs, but many people see such a situation as a problem. Certain institutions/universities set their own rules and systems which require IRBs examination on broader range of research programs involving human subjects such as social science research.

${ }^{30}$ D.R.J. Macer. Ethical considerations in the HapMap project: An insider's personal view. Eubios Journal of Asian and International Bioethics 2003; 13: 125-127.

${ }^{31}$ Suda and Macer, op. cit. note 22.

${ }^{32}$ Ministry of Education, Culture, Sports, Science and Technology. 2004, op cit.

${ }^{33}$ B.M. Knoppers and R. Chadwick. Human genetic research: emerging trends in ethics. Nature Reviews Genetics 2005; 6: 75-79.

${ }^{34}$ See the Report of New Zealand Royal Commission on Genetic Modification (2002) http://www.mfe.govt.nz/publications/organisms/royal-commission-gm/index.html

${ }^{35}$ H. Hirakawa. 2003. Hukakujitsu sei, kachi, koukyou sei wo meguru risk communication no sho mondai - risk governance no hi koukyou ka ni koushite. Presented at the annual conference of Public Policy Studies Association 2003.

http://hideyukihirakawa.com/sts archive/regulatory/PPSA/hirakawa20030615.pdf

${ }^{36}$ Weinberg, op. cit. note 24 .

${ }^{37}$ House of Lords Select Committee on Science and Technology. 2000. Science and Society $3^{\text {rd }}$ Report. London. HMSO. 